Magdalena Kapińska

10.15290/cr.2016.15.4.07

University of Białystok

\title{
Memory-dependent grief in Octavia Butler's Fledgling
}

\begin{abstract}
The article explores grief as a memory-related emotional response to the loss of loved ones as presented in Octavia Butler's fantasy novel Fledgling. The article deals with the inability to experience grief due to memory loss and the struggles that come with it. The reasons behind the inability of the main character to experience grief and its meaning are investigated. Two potential explanations are explored: the inability to experience grief as a result of general dissociative amnesia caused by the traumatic experience of witnessing the slaughter of one's family and being left on the brink of death, and the possibility of the loss of affect induced by overwhelming feelings of loss. The grief over a person of whom the memories are intact is analyzed and contrasted with the lack of grief for the forgotten relatives. The idea of continuing bonds connected with the mourning process is briefly presented and illustrated using examples from Fledgling. The theory of five stages of grief formulated by the psychiatrist Elisabeth Kübler-Ross is briefly introduced. Some of the stages of Kübler-Ross's theory (denial, anger and acceptance) are illustrated through the analysis of the grief experienced by the main character. The distinct inability to govern or temper the emotional response to death is presented. Grief is also briefly introduced as a possible bonding instrument.
\end{abstract}

Keywords: grief, mourning, memories, amnesia, emotions.

Death is a part of life one can never escape. One needs only to look around to find a multitude of stories of the dead and the ones who mourn them. Death and grief are inextricably connected. As Elizabeth Kübler-Ross and David Kessler wrote: "Grief is one of life's passages we all experience. It is one of life's equalizers, a shared experience for every man and woman who lives" (229). Although grief is a universal response to death, its experience is not, as every person grieves in their unique way. In Octavia Butler's science fantasy novel Fledgling the author approaches the subject of grief and explores how one deals with the aftermath of death. Butler's story also poses a question: How do you grieve if you do not remember those you have lost?

To analyze how the matter of grief as a memory-related emotional reaction is presented in Fledgling, first I would like to establish what meaning of grief I will refer to. As Kübler-Ross and Kessler observe, "[g]rief is the intense emotional response to the pain of a loss. It is the reflection of a connection that has been broken" (227). Although people come to form connections with inanimate objects or places, and grief can be associated with any loss, I would like to focus on grief as a response to the loss of a person, someone whom we cannot replace. When somebody loses a loved one, they do not move on as easily as when they lose an object, even though they may have had 
an unusually strong emotional connection to it. The death of a person close to us begins mourning, which William Worden defines as "the process that one goes through in adapting to the death of the person", whereas grief, as he explains it, is "the experience of one who has lost a loved one to death" (17, italics in original). It seems logical, then, to state that grief is an intricate part of the mourning process. One cannot truly mourn if one does not grieve. Although Vamik Volkan postulates that grief is only "the initial reaction" (91) to the loss, I am partial to different outlooks, including that of Worden, which does not limit the experience of grief to the beginning of the mourning process but looks at grief as present throughout the entirety of the process.

Octavia Butler was an African American writer, and most of her works belong to the science fiction genre. The majority of her writing concerns the topic of race, and Fledgling does not deviate from her other writing subjectwise. The main character in Fledgling is the result of a science experiment which mixed the DNA of an Ina (a species introduced in the novel) and an African American person. Because of her uniqueness the main character is approached in a tentative manner by some and unequivocally rejected by others. Although race plays a role in the plot of the novel, this article will not explore this aspect of the story in any significant manner.

In Fledgling the main character is thrown into a life which is permeated by the emotions one experiences when faced with death, as the whole community she lived with has been killed. Shori, the main character, suffers from amnesia, and her first memories are of entering " $[t]$ he world made strange by death" (Bennet, 346). The readers learn together with Shori what happened on the day that those closest to her met their fate. When she emerges from a cave, which was her shelter at the time of healing from the injuries which left her on the brink of death, one of the first images she sees is the site of the village, which has been burned to the ground. No memories are stirred by the images, and Shori does not recall that the place was once her home, despite having an emotional reaction to what she sees. She thinks: "That felt right. It felt like something I would want - living together with other people instead of wandering alone" (Butler, 5). In spite of the lack of recollection of any bond linking her to other people, she yearns for it. Later on, when she explains how she found the site of the village, she remarks that no memories were involved. She clarifies: "Only a feeling that I'm somehow connected to this place. I came here when I was able to leave the cave where I woke up, but I didn't know why. It was as though my feet just brought me here" (Butler, 62). It seems as if her instincts overrode her conscious mind, and when she was seeking a safe place they led her to a place she once loved, though at the time could not recall. Through the account of the man who, as she learns, is her father, Shori discovers that the burnt village she has found was the community she lived in, and the victims were her family. Her father reveals what he knows to have occurred. He tells her: "Someone burned your mothers and your sisters as well as all of the human members of your family to death here. They shot the ones who tried to get out, shot them and threw most of them back into the fire" (Butler, 64). Although Iosif, Shori's father, and some members of his community searched for survivors, finding Shori was a surprise. How she managed to survive is a mystery no one can explain. However, her dark skin and ability to withstand daylight are thought to have aided her in the escape. Iosif also confirms Shori's suspicions that she 
is not human. He provides her with basic information about Ina - the species of which they are members.

We live alongside, yet apart from, human beings, except for those humans who become our symbionts. We have much longer lives than humans. Most of us must sleep during the day and, yes, we need blood to live. Human blood is most satisfying to us, and fortunately, we don't have to injure the humans we take it from. But we are born as we are. We can't magically convert humans into our kind. (Butler, 63)

The information Shori receives clarifies many issues that have haunted her since she woke up without her memory, but they also raise a number of questions, the answers to which she will seek throughout the story. Learning who she is, what happened to her loved ones, and that her father and members of his community searched far and wide for the survivors and the killers, leads her into revealing that she has killed someone.

Despite not remembering her father and not being completely certain she can trust him, she confesses that she killed a man soon after she awoke in the cave. She divulges: "Someone found me as I was waking up in the cave... I was regaining consciousness, and someone found me. I didn't know at the time that it was ... a person, a man. I didn't know anything except ... I killed him" (Butler, 65). As it turns out, the man was a member of Iosif's community who was helping with the search after the tragedy. Iosif's reaction to Shori's confession is the first glimpse she gets into how someone feels when they lose a loved one. "He stared at me, first with anger and grief, then, it seemed, only with sorrow" (Butler, 66). His emotional reaction is clearly visible. "I looked at him and saw his sorrow. He knew who the man was, and he mourned him. I shook my head. 'I'm sorry'” (Butler, 66). She repeats her apology and one can hear her own sadness in her voice. Possibly, she does not only feel guilty that she killed someone, but she also experiences guilt and sadness over the realization that she caused someone emotional pain.

Once Shori is reunited with her father and brothers' community she observes the emotional reactions others exhibit in connection to the death of their loved ones. She sees how the memories cause others to experience emotions she does not have: "He smiled, apparently taking pleasure in his memories, then his expression sagged into sadness" (Butler, 78). Although she does not feel the same as they do about the death of the members of her community, due to her lack of recollection of them, she realizes that those emotions are precious: "I found that I almost envied his pain. He hurt because he remembered" (Butler, 74). Shori desires the ability to reclaim her memories, which for her is also the only way to reclaim the emotional bond with the family she has lost.

Unfortunately for her, Shori's father, brothers and their whole community are killed before she can reconnect with the forgotten relatives, or receive the answers and help which she desperately needs. When she finds another community of Ina she witnesses even more bereavement. She struggles with the fact that unlike others she cannot deal with the death of her family in a similar way. "Sometimes I recall disconnected bits about myself or about the Ina in general. But I've lost 
my past, my memory of my families, symbionts, friends... The people of my families who are dead are so completely gone from me that I can't truly miss them or mourn them because, for me, it's as though they never existed" (Butler, 207). She seems to express the wish for the ability to grieve for her dead and, once the mourning process comes to an end, to be able to move on with her life. However, this is not possible for her, as she does not grieve. The fragments of memories and knowledge that she keeps recovering seem to make her distraught, even more than she already is, as they seem to intensify the feeling that she is missing something, even though she neither truly misses it or recalls having cared about it in the first place.

Characters in the novel express their grief in different manners, most of which are clearly visible. Shori, however, does not express grief for the lost relatives as she is not able to produce the emotional reaction because of her lost memories. Although once perceived as something abnormal, "[t]he absence of grief is no longer seen, by definition, as pathological" (Hall). Albeit not considered pathological, grief's absence in the face of the loss of a loved one may seem questionable. One could speculate that there was no love or other significant emotional connection between the deceased and the person who is supposed to grieve to begin with. However, Shori's situation is more complex than usual mourning processes, and because of that the expectations concerning the mourning process should also be different.

One of the characters in the novel ponders whether Shori's loss of memory is a way of coping with the severe feelings of bereavement. "I wonder if that's part of why your memory is gone, not just because you suffered blows to the head, but because of the emotional blow of the death of all your symbionts, your sisters, and your mothers - everyone. You must have seen it happen. Maybe that's what destroyed the person you were" (Butler, 267). The character's musings that Shori's memory loss is the result of emotional distress may not be that far off when it comes to dealing with her traumatic experiences.

When a person experiences a traumatic event they can react in various ways. One of the possibilities is dissociative amnesia, which "is an inability to recall important autobiographical information" (DSM V, 298). The American Psychiatric Association distinguishes three types of dissociative amnesia based on what kind of information a person cannot remember: localized amnesia, selective amnesia, and generalized amnesia. Generalized amnesia means that someone has no recollection of their life and their identity, which is the case with Shori. According to the fifth edition of the Diagnostic and Statistical Manual of Mental Disorders, generalized dissociative amnesia is rare, and those who experience it may "lose previous knowledge about the world (i.e. semantic knowledge) and can no longer access well-learned skills (i.e. procedural knowledge)" (298-299). Shori seems to be suffering from dissociative amnesia as she does not remember either her personal identity or any events from her past. Throughout the course of the novel she tries to recall certain events or people, but she is unsuccessful.

I shut my eyes and tried to find something of this woman in my memory-something. But there was nothing. All of my life had been erased, and I could not bring it back. Each time I was confronted with the 
reality of this, it was like turning to go into what should have been a familiar, welcoming place and finding absolutely nothing, emptiness, space. (Butler, 132)

The failures to regain her memories cause continuous disappointment, but Shori does not abandon her quest to bring back her lost personal past. Instead of admitting defeat she seeks information from those surrounding her. She also does not recall information about the unique species she is a part of. She has to learn everything once again, although some of her well-learned skills manifest themselves once she attempts to use them: "I read aloud from the first [book] in a language that I could not recall having heard or seen. And yet as soon as I opened the book, the language seemed to click into place with an oddly comfortable shifting of mental gears" (Butler, 187). The skill of using the Ina language comes back to her immediately once she is exposed to it. The fact that one of the forgotten skills is so easily recovered seems to give Shori hope that some of the other pieces of her life will also return. She wonders what else about her past will reveal itself when her mind is prompted by an everyday situation. Since "[s]ome episodes of dissociative amnesia resolve rapidly ... whereas other episodes persist for long periods of time" one cannot be sure when or even if they will regain their memories (DSM V, 299). Although Shori seems to recover snippets of her past, the memories about her dead loved ones or about how she felt about them do not return, and it seems that they may be gone forever. If in fact they never return, she will never be able to fully mourn those that were close to her.

Shori's experience of the traumatic event, which is the slaughter of her family, could explain the loss of her memory, which in turn prevents her from properly mourning her loved ones. However, if we were to isolate her inability to experience grief from her amnesia, we could assume it is due to the loss of affect.

Donald Gustafson in his article on grief writes that "grief can express itself in what is called 'a loss of feeling or affect,' ... this condition of psychological immobilization is brought about by feelings of loss, anguish, fear, pain, and the rest" (465). Each person reacts differently to the death of a person dear to them; some have more extreme reactions than others. "Loss of affect is exemplified by an individual who lacks any apparent emotion in an emotionally stimulating situation, or by an individual who displays inappropriate emotions and so 'loses' the affect that belongs in the situation" (Herron, 37). The inability to produce the appropriate emotional reactions in certain situations can have various causes. When we consider the lack of grief after the death of a loved one it can have something to do with, for instance, the kind of relationship we had with the deceased. We may not grieve if the relationship was ambivalent, abusive or dependent (Worden, 127-128). Sometimes the manner in which the loss had occurred may prevent us from grieving. If the loss cannot be confirmed, as often happens when someone goes missing, grief may not come (Worden, 129). If we contemplate Shori's lack of grief, perhaps the theory relating to the number of the people one loses is the most suitable.

In Grief Counseling and Grief Therapy Worden mentions an instance where a patient did not grieve after a multiple loss. He recounts: "The sheer volume of people to be grieved was over- 
whelming, and in a case like this, it can seem easier to close down the mourning process altogether" (Worden, 130). Shori has suffered a monumental loss. She lost every person she ever cared about, and in the light of her situation one could postulate that Shori suffers from the loss of affect, as she does not exhibit any emotional reactions to the death of her relatives. If we take her amnesia out of the equation, her inability to grieve seems not to be so uncommon as one could presume. One can never know if the loss of affect will persist indefinitely, or if it will pour out one day as it was simply delayed. (I will discuss the notion of delayed grief later on, when Shori's experience of grief over a lost symbiont is analyzed.) The fact that she is Ina meant that her grief should be even more severe than that of a human, a notion she is reminded of and later learns on her own, and thus her lack of grief seems highly unusual. "We Ina don't handle loss as well as most humans do. It's a much rarer thing with us, and when it happens, the grief is ... almost unbearable" (Butler, 265). One could try and explain Shori's state in various ways. She could have dissociative amnesia, which severs her emotional connection with the past, or she could suffer from the loss of affect, and her amnesia is a result of the physical injuries she had suffered. We can theorize but we cannot be certain. The only undeniable thing is that she does not grieve after the family she does not remember.

In "Mourning and Melancholia" Sigmund Freud talked about the normal process of grieving and its extreme case, which he referred to as melancholia. He wrote: "In mourning it is the world which has become poor and empty; in melancholia it is the ego itself" (22). If one were to understand Freud's words literally, Shori would clearly suffer from melancholia, as she is truly empty after her loss: she has no memory and no identity; she has to create them from the very beginning. Of course, one should not rely on the literal meaning of the words. Instead, what we can infer from Freud's words is that both in the usual and the extreme instances of mourning something is askew in the life of the mourner. "Freud advocated killing off the trace of the other in the self as a means to reestablish psychic health", by which he seemed to mean to eradicate any remaining emotion one has for the deceased (Clewell, 60). However, this idea has its source in his initial work concerning grief, which is "Mourning and Melancholia". In the years following the publication of "Mourning and Melancholia" Freud revised his findings. From his subsequent publications one can learn that in his view "[w]orking through [a loss] no longer entails abandoning the object and reinvesting the free libido in a new one; ... [it] depends on taking the lost other into the structure of one's own identity, a form of preserving the lost object in and as the self" (Clewell, 61). His idea of making the deceased a part of one's identity and only then being able to move on seems to be the notion which is embraced today by many. Once, "the idea of successful grieving require[d] 'letting go"' (Hall) of the lost loved one. Nowadays, however, the idea of continuing bonds which were forged between us and the deceased throughout the duration of the relationship has been welcomed. "This idea represents recognition that death ends a life, not necessarily a relationship. Rather than 'saying goodbye' or seeking closure, there exists the possibility of the deceased being both present and absent" (Hall). Although the dead are physically absent from our lives, they remain present in them through our memories and emotions. 
In Fledgling we can see an example of the idea of continuing bonds. Because Shori does not have either the memories or the emotional connection to the deceased, the bonds she formed seem to have already been broken. Nevertheless, the members of the community she temporarily lives in try to encourage her to take advantage of the bonds that are still present in others. During the trial a member of the Ina community advises Shori: "You must bring them [her family] into the room with you and stand them beside you whenever you can" (Butler, 222). The idea of bringing the dead back to life through our memories and imagination, according to Tammy Clewell, is something that Freud included in the mourning process. It seems that some mourners restore "the existence of the lost other in the space of the psyche, replacing an actual absence with an imaginary presence" (Clewell, 44). Being able to have the dead present and to talk with them is something that many mourners yearn for, and so does Shori. Although she cannot bring her dead even into the imaginary presence, as she has no emotional bonds to rely on, she attempts to do it by using the bonds of others. Through the stories about her dead family she regains small pieces of them. However, the most visible continuation of bonds can be seen in Celia and Brook, symbionts of the members of Iosif's community. Due to their physical dependency on the particular Ina of whom they were symbionts, they not only suffer emotionally but also physically after the death of their Ina. In order to survive Brook and Celia have to break the physical connection to the deceased Ina and try to create a new connection between them and Shori. However, it is not so easily done as both their bodies and their minds yearn to remain connected to the loved ones who died. They fight to create new connections, and at the same time remain connected to their dead. "I knew they smelled wrong, but if he knew what had happened to my family, he must know why they smelled the way they did - of both the dead and the living" (Butler, 143). This seems to be what stands behind the idea of continuing bonds. We struggle to stay connected with those that are no longer with us in such a way that will allow us to create new bonds, to continue living without abandoning those who cannot accompany us forward, but without whom our past would not be complete, just like Celia and Brook. Although the struggle is painful, especially at the beginning, discovering that new bonds bring us joy seems to allow a person to reach the realization that the past, the present and hope for the future can coexist within us, and allows us to simply live.

In Fledgling Octavia Butler contrasts Shori's lack of grief for those who were erased from her memory with the grief for a person she remembers. Despite doing her utmost to reclaim her past and regain the memories of emotional connections she had with her loved ones, Shori does not succeed. However, when Theodora, one of Shori's symbionts whom she loved, is killed, the grief which would not come for her lost family pours out while she struggles to contain it.

Although everyone grieves in their own way, there are various theories which explore the emotional reactions to loss, for instance Stroebe and Schut's Dual Process Model of Grief, and Worden's Task-Based Model. There are also multiple views of grief as a series of stages, for example the models of Bowlby and Parkes, but probably the most widely recognized stage model is the one put forward by Elisabeth Kübler-Ross (Hall). Kübler-Ross formulated a model of five stages of dying, which nowadays are also commonly used with reference to grief and mourning. These 
five stages are: denial, anger, bargaining, depression and acceptance (Kübler-Ross, 31,40,66,69,91). The stages differ in intensity and length, may happen in various order, and not all must occur in every person's mourning process. Although some question all stage models of grief, these theories have been frequently incorporated in the education of medical specialists (Hall). Because of this I would like to explore some of the stages presented by Kübler-Ross, as I believe we can easily spot some of them in Octavia Butler's novel.

At first Shori is in denial about what has happened to Theodora: "I was not truly seeing or understanding what was happening around me. I could not believe my Theodora was dead. It made no sense that she would be dead. None" (Butler, 251). The idea that someone she loved, someone close to her, no longer had a place in this world is unimaginable for her. She wants to isolate herself and find a reason for what happened, to make sense of something that seems senseless. Shori quite quickly moves on from denial to anger.

Kübler-Ross explained that "anger is displaced in all directions and projected onto the environment at times almost at random" (Kübler-Ross, 40). When Shori examines Theodora's body she unexpectedly starts shouting at the person nearest to her, and only after her outburst does she realize that it was someone whom she holds dear. "Someone spoke to me, came near, and I shouted, 'Let me alone! Get away from me!' A moment later, I realized that I had shouted at Wright, my first. I had told him to go away. Stupid of me. Stupid!" (Butler, 253). The anger overtook Shori in that instance; she was not in control of herself, but as the outburst of the anger passes she feels regretful of her action. Later, Shori's anger is more focused; she is angry at the person responsible for killing her symbiont. "I had to do something. What I wanted to do was tear her apart with my teeth and hands" (Butler, 266). Once she is able to guide her anger in a specific direction she no longer has random outbursts of anger. Despite wanting to avenge her loved one, Shori cannot do it at the time, as the rules of Ina society have to be abided by. She needs to rein in her anger and try to remain composed.

Shori needed to find a way to function after losing Theodora, as she was in the middle of the trial, whose goal was to find justice for the family she lost. She wanted to restrain her emotional reaction: "I could not dissolve emotionally and lose myself in grief. I did not dare. There was no time" (Butler, 253). However, it is not easy to control one's emotions, especially when they are heightened. It is hard to try and go about your life as if nothing happened. Shori observes that "It hurt to say her name" (Butler, 255) when she mentioned Theodora. It seems that when we lose someone, the memories that once brought us joy now bring us pain. The emotional pain is a part of grieving, and Shori wanted to be able to experience and deal with her grief: "I wanted to run away from these strangers, find a dark corner, and huddle there rocking my body back and forth, moaning and mourning" (Butler, 258). Even though she tried, she could not hide her emotional state from others. Preston remarks on Shori's inability to hide her grief: "You stand there hugging yourself as though you were trying to hold yourself together" (Butler, 265). He compares Shori's efforts to stay composed to an attempt not to fall to pieces. Maybe she is trying to remain whole. So many pieces of her had been stolen that she may crumble if something or someone does not help 
her stay upright and glue herself back together in such a way that the missing pieces do not prevent her from continuing to live.

Some emotions can be alleviated or avoided through specific behavior or activities, for instance anger can lose its intensity after intense exercise, or we can avoid situations that would cause us to experience fear. However, there is no action one can undertake in order to lessen one's grief, or a way to ward it off. It is out of one's hands (Gustafson, 469-470). Gustafson wrote that although we can regulate some of our emotions "[t]he will has little or no force against grief... Only grief's manifestations can be controlled and then only in part" (Gustafson, 470). Shori seems to be able to control the manifestations of her grief, regardless of the emotional turmoil that is going on inside of her. Her actions bring Theodora's killer to justice, and in the end it is Shori that kills her symbiont's murderer. The fact that Theodora was avenged seems to bring Shori much closer to the stage of acceptance, and not only when the death of the person she loved was concerned, but also when it came to her lost memories and the relatives she lost twice: once through their death and once through her amnesia. "They were all gone. The person I had been was gone. I couldn't bring anyone back, not even myself. I could only learn what I could about the Ina, about my families. I would restore what could be restored" (Butler, 310). Through acceptance Shori is able to start a new life for herself, and the grief that she both witnessed and experienced could, in a way, help her with that.

However, is Shori's mourning process truly over? One of the characteristics of the Ina is that they grieve very deeply. Some members of Ina society questioned Shori's low intensity of grief: "[T]he Dahlmans expected you ... to be out of your mind with pain, grief, and anger, to be a pitiable, dangerous, crazed thing" (Butler, 265). To the surprise of many Shori was nowhere near being defeated by her grief, although she was expected to have been. Even though she had emotional bonds linking her to Theodora, her grief was inappropriately moderate in comparison to the loss. Some members of the Ina community argued that Shori's hybridity was the reason for her unusual grieving. They claimed that the part of her which is human overshadows the Ina in her, and because of that her emotional response is different from that of the ordinary Ina.

No one can be certain of the truth of anything you say because you are neither Ina nor human. Your scent, your reactions, your facial expressions, your body language-none of it is right. You say your symbiont has just died. If that were so, you would be prostrate. You would not be able to sit here telling lies and arguing. True Ina know the pain of losing a symbiont. We are Ina. You are nothing! (Butler, 272)

Shori's grief was certainly different than expected, she did not meet the standards of a grieving Ina. However, Shori might not have expressed the full extent of her emotional turmoil; she might have suffered from delayed grief. In the case of delayed grief "the person may have had an emotional reaction at the time of the loss, but it is not sufficient to the loss. At a future date the person may experience the symptoms of grief over some subsequent and immediate loss, and the intensity of his or her grieving will seem excessive" (Worden, 140). The timing of Thodora's death was very unfortunate (not that any death can really be fortunately placed), as Shori was in the middle of 
doing her utmost to find justice for her dead family. The circumstances might have caused Shori to curb her immediate reaction to her symbiont's death. It might be that in the future, when some time has elapsed and some of the chaos in her life has dissipated, the delayed emotions would come.

Grief can be a powerful instrument in creating relationships. As Gustafson emphasizes, "[F] rom the psychiatric literature there is ample evidence of the bonding that grief, tragedy, and the like produce among both individuals and groups" (459). In Fledgling the tragedy concerning the Ina allows the main character to find her way into a closed community. Moreover, the grief that others experience, and the understanding of the suffered loss, allows Shori to create bonds with the members of the community more easily. Shortly after her arrival she becomes a part of the community. The Gordons assure her: "You're with us now. You aren't alone" (Butler, 153). The new relationships created amongst the grief may be fragile, as they were forged in times of distress, but they are also a sign that one does not give up but continues to live, creating new memories, and not only dwelling on reminders of the past. Perhaps the created ties with the Ina community will aid Shori in creating a new beginning and possibly regaining some of the lost memories.

In Octavia Butler's novel the reader can see that memories play an imperative role when it comes to grief. The reader can see how one struggles when one is denied the possibility to grieve, and how one suffers when one is inevitably forced to experience it. The reader sees that the knowledge that you have loved someone cannot replace the memory of the feeling; they do not equate. Knowing that you once felt a certain way does not evoke emotional responses the same way the recollection of those feelings does. Memories are crucial when it comes to grief, and although they may bring pain, they also allow us to keep the love alive long after someone is gone.

\section{References}

American Psychiatric Association. 2013. Diagnostic and Statistical Manual of Mental Disorders, Fifth Edition (DSM V). Arlington: American Psychiatric Association.

Bennet, Jill. 2002. "Art, Affect, and the 'Bad Death': Strategies for Communicating the Sense Memory of Loss." Signs 28.1, 333-351.

Butler, Octavia E. 2007. Fledgling. New York: Grand Central Publishing.

Clewell, Tammy. 2004. "Mourning Beyond Melancholia: Freud's Psychoanalysis of Loss.” Journal of the American Psychoanalytic Association 52.1, 43-67.

Freud, Sigmund. 1917. "Mourning and Melancholia." The Complete Edition of the Psychological Works of Sigmund Freud 14. Ed. and trans. James Strachey. 1957 Rpt. in On Freud's "Mourning and Melancholia". 2009, 19-34.

Gustafson, Donald. 1989. “Grief.” Nô̂s 23.4, 457-479.

Hall, Christopher. 2011. "Beyond Kübler-Ross: Recent developments in our understanding of grief and bereavement." InPsych 33.6. 20 Feb. 2016 www.psychology.org.au/publications/inpsych/2011/ december/hall/.

Herron, William G., Kantor, Robert E. 1968. “Loss of Affect.” The Journal of Psychology 70. 1, 35-49. 
Kübler-Ross, Elisabeth, and David Kessler. 2005. On Grief and Grieving: Finding Meaning of Grief through the Five Stages of Loss. New York: Scribner.

Kübler-Ross, Elisabeth. 2009. On Death and Dying: What the Dying Have to Teach Doctors, Nurses, Clergy and their own Families. London, New York: Routledge.

Volkan, Vamik D. 2009. "Not letting go: from individual perennial mourners to societies with entitlement ideologies." On Freud's "Mourning and Melancholia". Ed. Leticia Glocer Fiorini, Thierry Bokanowski, Sergio Lewkowicz. London: Karnac, 90-109.

Worden, J. William. 2009. Grief Counseling and Grief Therapy: a Handbook for the Mental Health Practitioner. New York: Springer Publishing Company. 